Article

\title{
Study of Static Recrystallization Kinetics and the Evolution of Austenite Grain Size by Dynamic Recrystallization Refinement of an Eutectoid Steel
}

\author{
Cesar Facusseh ${ }^{1, *}$, Armando Salinas ${ }^{1}$, Alfredo Flores ${ }^{1}$ and Gerardo Altamirano ${ }^{2}$ \\ 1 Centro de Investigación y de Estudios Avanzados del Instituto Politécnico Nacional (CINVESTAV), \\ Unidad Saltillo, Av. Industria Metalúrgica, 1062, Parque Industrial Saltillo-Ramos Arizpe, \\ Ramos Arizpe 25900, Mexico; armando.salinas@cinvestav.mx (A.S.); alfredo.flores@cinvestav.mx (A.F.) \\ 2 Instituto Tecnológico de Saltillo, Blvd. Venustiano Carranza, 2400, Col. Tecnológico, Saltillo 25280, Mexico; \\ galtamirano@itsaltillo.edu.mx \\ * Correspondence: cesar.facusseh@cinvestav.edu.mx; Tel.: +52-844-438-9600 (ext. 8549)
}

Received: 20 October 2019; Accepted: 25 November 2019; Published: 29 November 2019

\begin{abstract}
Interrupted and continuous hot compression tests were performed for eutectoid steel over the temperature range of 850 to $1050^{\circ} \mathrm{C}$ and while using strain rates of $0.001,0.01,0.1$, and $1 \mathrm{~s}^{-1}$. The interrupted tests were carried out to characterize the kinetics of static recrystallization(SRX) and determinate the interpass time conditions that are required for initiation and propagation of dynamic recrystallization (DRX), while considering that the material does not contain microalloying elements additions for the recrystallization delay. Continuous testing was used to investigate the evolution of the austenite grain size that results from DRX. The results indicate that carbon content accelerates the SRX rate. This effect was observed when the retardation of recrystallization due to a decrease in deformation temperature from 1050 to $850{ }^{\circ} \mathrm{C}$ was only about one order of magnitude. The expected decelerate effect on the SRX rate when the initial grain size increases from 86 to $387 \mu \mathrm{m}$ was not significant for this material. Although the strain parameter has a strong influence on SRX rate, in contrast to a lesser degree of strain rate, both of the effects are nearly independent of the chemical composition. The calculated maximum interpass times that are compatible with DRCR (Dynamic Recrystallization Controlled Rolling), for relatively low strain rates, suggest that the onset and maintaining of the DRX is possible. However, while using the empirical equations that were developed in the present work to estimate the maximum times for high strain rates, such as those observed in the wire and rod mills, indicate that the DRX start is feasible, but maintaining this mechanism for $5 \%$ softening in each pass after peak strain is not possible.
\end{abstract}

Keywords: eutectoid steel; pearlite interlamellar spacing; austenite grain refinement; interpass time; static recrystallization (SRX); dynamic recrystallization (DRX); metadynamic recrystallization (MDRX); dynamic recrystallization controlled rolling (DRCR)

\section{Introduction}

It is well known that increasing carbon content increases the strength of steel, but usually at the expense of fracture toughness. Grain refinement through thermal or thermo-mechanical treatments is a powerful tool for the simultaneous improvement of strength and fracture toughness. This is the main metallurgical reason motivating the development of HSLA (High Strength Low Alloy) steels [1]. In low $C$ steels, the ferrite grain size represents the most important microstructural parameter, because a strength and toughness increase can be achieved as a result of ferrite grain refinement from refined austenite grains. In high $C$ steels of eutectoid or hypereutectoid compositions, the strength and toughness are controlled by different microstructural parameters. Pearlite interlamellar spacing 
is primarily responsible for strength in high $\mathrm{C}$ steel. Decreasing the spacing increases the strength. Decreasing the transformation temperature can refine interlamellar spacing [2-4]. However, it has been shown that interlamellar spacing is also dependent on the prior austenitic grain size for a constant transformation temperature $[2,5,6]$. Prior austenitic grain size also influences ductility and fracture toughness, but, in this case, on a greater level than the interlamellar spacing of pearlite $[2,7,8]$. Thus, the austenitic grain size for high carbon steels also plays an important role in improving their mechanical properties.

Pearlitic steels of eutectoid and hypereutectoid composition are extensively used for different engineering applications, because they offer a useful combination of strength, ductility, and wear resistance. The principal application of these steels is in rails and railroad wheels. They are also widely used as reinforcement wires in the fabrication of automobile tires, conveyors, hoses, and bunched arrays for bridge cables. For all of these applications, the pearlitic wire rods are cold drawn into wires, which achieve the highest strength of all steel products, up to approximately $6 \mathrm{GPa}[9,10]$. Cold drawn high carbon steel wire rods are produced from continuous casting billets, which are pre-heated and then hot rolled. Finally, they are isothermally transformed in lead or salt baths at the temperatures range of $1050-850{ }^{\circ} \mathrm{C}$ [11] or water cooled to temperatures between 960 and $750{ }^{\circ} \mathrm{C}$ for subsequent continuous cooling by air-blasting on a conveyor [9]. Producing a fine pearlite microstructure is the aim of these heat treatments.

Optimization of mechanical properties of wire rods for cold drawing process begins during hot deformation. This is because recrystallization plays an important role in the grain refinement of the austenite. There are three types of recrystallization that can take place during or after hot deformation: dynamic (DRX), metadynamic (MDRX), and static recrystallization (SRX). During industrial hot rolling, the length of the interpass time plays an important role. When the interpass time is long, as in plate rolling in reversing mills, there is sufficient time for the occurrence of SRX or carbonitride precipitation in $\mathrm{Nb}$ microalloyed steels. On the other hand, when the interpass time is short, as in the finishing stages of rod rolling, there is no time for SRX and carbonitride precipitation. Under these conditions, strain accumulation takes place, which leads to the initiation and propagation of DRX [12]. This type of industrial processing is termed dynamic recrystallization controlled rolling (DRCR). Moreover, at relatively low temperatures, DRX is an alternative and effective softening mechanism that can produce further grain refinement [13].

Niobium is the most advantageous and effective microalloying element that is used in HSLA steels to delay the onset of recrystallization. For many years, small additions of $\mathrm{Nb}$ in the range of 0.03 to $0.05 \%$ (that can readily be dissolved at ordinary soaking temperatures) have been used to refine ferrite grain size in the final product as a result of austenite grain refinement by static and dynamic recrystallization retardation during controlled rolling [14].

For this reason, the recrystallization kinetics for niobium and other microalloyed steels has been extensively studied [15-27]. On the other hand, because only approximately $0.01 \% \mathrm{Nb}$ can be dissolved in austenite at $1200{ }^{\circ} \mathrm{C}$ for $0.8 \% \mathrm{C}$ [14], the austenite recrystallization kinetics in high carbon steels is relatively unexplored [28,29]. Moreover, the static softening rate during an interpass time of dynamically recovered or recrystallized hot deformed steel increases with carbon content. This is due to the increase in the diffusivity of vacancies, which enhances static recovery (SRV), SRX, metadynamic recovery (MDRV), and MDRX [28].

In the case of eutectoid steel without microalloying additions, it is of scientific and technological interest to establish the interpass time conditions that are required for strain accumulation before and after DRX and determine the grain refinement grade that might be achieved by continuous deformation with that mechanism. Therefore, the aim of the present work was to develop mathematical expressions that can be used to describe the evolution of the grain structure by DRX refinement and the SRX softening to predict the interpass time conditions for the initiation and propagation of DRX. Isothermal interrupted hot compression tests determined the SRX behavior during hot deformation of this high 
carbon steel. The evolution of the austenite grain size was studied by continuous hot compression tests and quantitative metallography.

\section{Materials and Experimental Techniques}

Table 1 shows the chemical composition of the material used in this investigation. This eutectoid steel was supplied by local producer as hot rolled rail steel stock. High temperature compression tests were carried out using a servo hydraulic universal testing machine (MTS System Corporation) that was equipped with an infrared radiation furnace. The compression test specimens were machined with dimensions of $15 \mathrm{~mm}$ in height and $10 \mathrm{~mm}$ in diameter and their cylinder axes parallel to the rolling direction of the as received rail steel. Each compression specimen and dies were lubricated with dry molybdenum lubricant to reduce the frictional effects.

Table 1. Chemical composition of the experimental steel.

\begin{tabular}{ccccccccccccc}
\hline Element & $\mathbf{C}$ & $\mathbf{S i}$ & $\mathbf{M n}$ & $\mathbf{S}$ & $\mathbf{C r}$ & $\mathbf{M o}$ & $\mathbf{N i}$ & $\mathbf{A l}$ & $\mathbf{C u}$ & $\mathbf{T i}$ & $\mathbf{V}$ & $\mathbf{F e}$ \\
\hline wt. $(\%)$ & 0.74 & 0.1174 & 0.8286 & 0.024 & 0.0194 & 0.0047 & 0.08 & 0.0121 & 0.109 & 0.001 & 0.001 & 98.152 \\
\hline
\end{tabular}

\subsection{Double-hit Interrupted Compression Tests}

Two sets of interrupted compression tests were carried out to determine the SRX kinetics behavior. The first set was designed to investigate the effect of temperature $\left(1050,950\right.$, and $\left.850{ }^{\circ} \mathrm{C}\right)$, strain rate $\left(0.01,0.1\right.$, and $\left.1 \mathrm{~s}^{-1}\right)$, and strain $(0.05,0.10$, and 0.15$)$ on the recrystallized fraction $\mathrm{X}_{\mathrm{SRX}}$ produced by the thermo-mechanical treatment, as illustrated in Figure 1a. The second of experiments set was performed to determine the effect of the initial austenite grain size $(387,195$, and $86 \mu \mathrm{m})$ on the recrystallized fraction (Figure 1b). In this experimental technique, the specimen is subjected to deformation with a given strain at constant strain rate, unloaded, and then soaked at the same temperature for interpass times of 1, 5, 10,30, and $100 \mathrm{~s}$ after heating and cooling to the deformation temperature. After that interruption period, the specimen is reloaded while using the same deformation conditions.

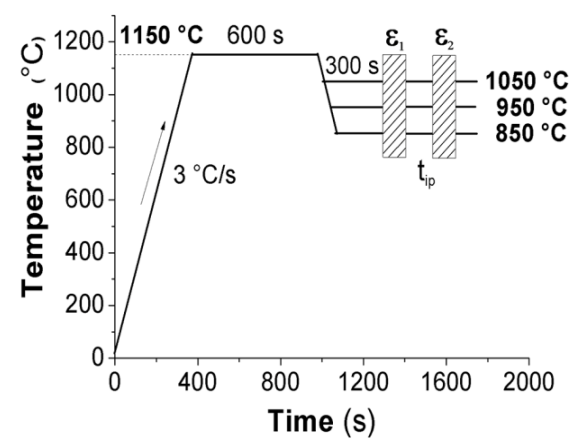

(a)

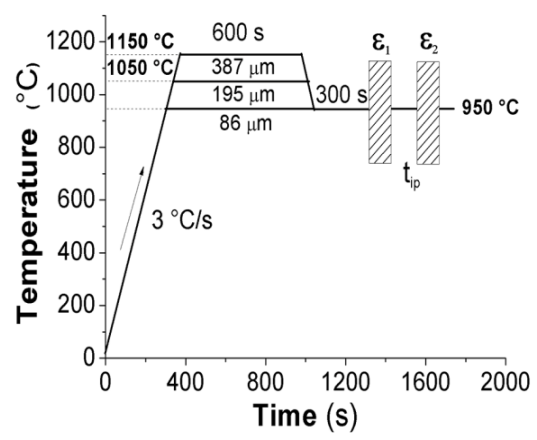

(b)

Figure 1. (a) Schedule 1 used for interrupted and continuous hot compression tests. (b) Schedule 2 employed for interrupted hot compression tests (initial grain size effect).

Double deformation testing is the most usual indirect measurement technique that is employed to determine fractional softening F.S. This technique provides a softening value with contributions from recovery and recrystallization. Although there are several methods for analyzing the true stress/strain curves, from double-hit deformation experiments, it is difficult to separate the individual effect of recovery and recrystallization.

The conventional $0.2 \%$ offset method usually results in higher softening values than those that were obtained from the recrystallized fraction direct measurements by quantitative metallography. In this method, the contribution of recovery softening to F.S. results in being $20 \%$ at the shortest 
interruption times [30]. The back extrapolation [19] and mean flow stress [15] are the other techniques reported in the literature to quantify the F.S. These methods significantly reduce the contributions of recovery to F.S. Li et al. [16] performed a comparison between the $0.2,2 \%$ offset and the mean flow stress methods and reported that the $2 \%$ offset technique is the best for minimizing the recovery effect.

Perttula et al. [31] have suggested that a comparison of flow stresses at larger true strains results in better estimations of F.S. without recovery contribution. They confirmed the technique by direct recrystallization measurements by quantitative metallography. Figure 2 makes a comparison between three of the most commonly used methods to estimate the fractional softening (F.S.) from double-hit compression tests.

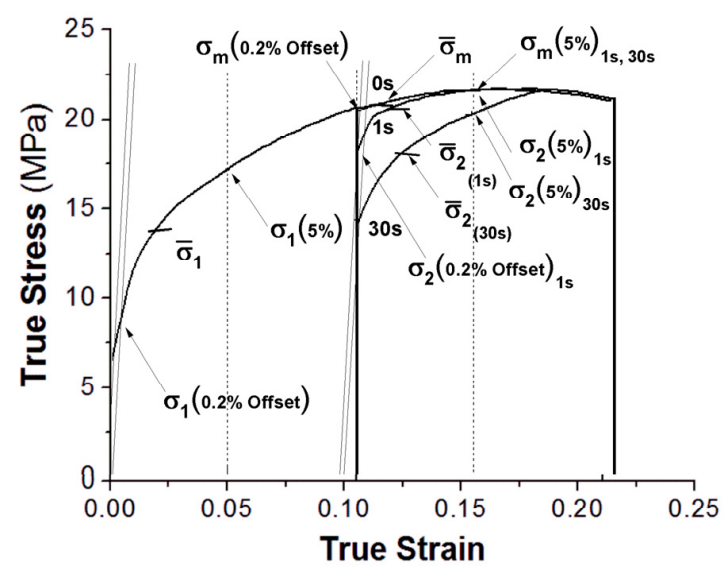

Figure 2. Comparison of $0.2 \%$ offset, mean flow stress and $5 \%$ strain methods used to estimate fractional softening at 0,1 and $30 \mathrm{~s}$ of interpass time from double-hit compression tests at $950{ }^{\circ} \mathrm{C}$ and $0.01 \mathrm{~s}^{-1}$.

The $0.2 \%$ offset method employs the following definition for fractional softening:

$$
\text { F.S. }=\frac{\sigma_{\mathrm{m}}(0.2 \% \text { offset })-\sigma_{2}(0.2 \% \text { offset })}{\sigma_{\mathrm{m}}(0.2 \% \text { offset })-\sigma_{1}(0.2 \% \text { offset })}
$$

where $\sigma_{\mathrm{m}}(0.2 \%$ offset $)$ is the end flow stress corresponding to the unloading strain in the first hit, $\sigma_{2}(0.2 \%$ offset $)$ and $\sigma_{1}(0.2 \%$ offset $)$ are the $0.2 \%$ offset flow stresses in the second and first hits, respectively. As can be seen in Figure 2 for an interruption time of $1 \mathrm{~s}$ (lower softening), $\sigma_{\mathrm{m}}(0.2 \%$ offset $)>\sigma_{2}(0.2 \%$ offset $)$, therefore the method results in fractional softening value different of zero. Fractional softening (F.S.) in terms of mean flow stress using a similar definition to the Equation (1):

$$
\text { F.S. }=\frac{\bar{\sigma}_{\mathrm{m}}-\bar{\sigma}_{2}}{\bar{\sigma}_{\mathrm{m}}-\bar{\sigma}_{1}}
$$

where $\bar{\sigma}_{2}$ and $\bar{\sigma}_{1}$ are the mean flow stresses for the second and first stress-strain curves, respectively. The $\bar{\sigma}_{\mathrm{m}}$ value is the mean flow stress for the second curve corresponding to zero softening $(0 \mathrm{~s}$ interruption time). In Figure 2 the $\bar{\sigma}_{\mathrm{m}}-\bar{\sigma}_{2}(1 \mathrm{~s})$ value represents the material softening from $1 \mathrm{~s}$ of interpass time. Thus, the method results in a fractional softening very close to zero. Finally, the fractional softening corresponding to the $5 \%$ strain method is evaluated, as follows:

$$
\text { F.S. }=\frac{\sigma_{\mathrm{m}}(5 \%)-\sigma_{2}(5 \%)}{\sigma_{\mathrm{m}}(5 \%)-\sigma_{1}(5 \%)}
$$

where the $\sigma_{\mathrm{m}}(5 \%)$ value is the true stress in the zero softening curve at strain of $5 \% . \sigma_{2}(5 \%)$ and $\sigma_{1}$ $(5 \%)$ are the flow stresses at strain of $5 \%$ in the second and the first hits, respectively. In contrast to the previous methods, in this case the stress $\sigma_{\mathrm{m}}(5 \%) 1 \mathrm{~s}, 30 \mathrm{~s}=\sigma_{2}(5 \%) 1 \mathrm{~s}$, for the $1 \mathrm{~s}$ interruption time curve, therefore the fractional softening (F.S.). is equal to zero. This is due to the effect of recovery 
softening in austenite being limited at larger strains. Thus, after the interruption period and reloading, the flow stress quickly attains the continuous (zero softening) curve and it remains away from the strain of $5 \%$ measurement point, as illustrated for the $1 \mathrm{~s}$ curve in Figure 2. Therefore, the $5 \%$ strain method was used to quantify the recrystallized fraction $X_{S R X}$ while assuming that it is equal to the fractional softening (F.S.) calculated by this method.

\subsection{Continuos Compression Tests}

Continuous hot compression tests were performed to investigate the austenite grain structure evolution caused by DRX refinement. These compression tests were carried out to study the effects of temperature $\left(1050,950\right.$, and $\left.850{ }^{\circ} \mathrm{C}\right)$ and the strain rate $\left(0.001,0.01\right.$, and $\left.0.1 \mathrm{~s}^{-1}\right)$ on the austenite grain size under the schedule in Figure $1 \mathrm{a}$ at true strain of 0.8 , followed by water quenching. Average grain size was measured while using the method that was described in the ASTM standards [32].

\section{Results and Discussion}

\subsection{Interrupted Hot Compression Testing}

\subsubsection{Influence of Deformation Conditions on the Kinetics of Static Recrystallization}

Double-hit hot compression tests were performed at different temperatures, strain rates, strains, and initial austenite grain size in order to obtain mathematical expressions that can be used to describe the softening associated with SRX and evaluate the interpass time conditions for initiation and propagation of DRX for this high carbon steel. The 5\% strain method was employed to calculate the fractional softening from the true stress-strain curves that were obtained while using different interpass times. Figure 3 illustrates the results of the experiments performed at a temperature of $1050{ }^{\circ} \mathrm{C}$, a strain rate of $0.1 \mathrm{~s}^{-1}$, a strain of 0.1 , and interpass times from 0 to $100 \mathrm{~s}$. As can be seen, when the interpass time increases, the fractional softening also increases from $1 \mathrm{~s}$ of interruption time, which results in a fractional softening of $2 \%$. The second deformation curve obtained after $1 \mathrm{~s}$ of interruption time rapidly increases and attains the continuous curve (zero seconds curve) flow stress value. The fractional softening reaches a value of $96 \%$ when the interruption period is increased to $100 \mathrm{~s}$. Additionally, as can be seen, the stresses $\sigma_{1}(5 \%)$ and $\sigma_{2}(5 \%)$ are nearly equal, which indicates an almost total restoration of the deformed microstructure.

Figure 4 shows the effect of temperature, strain rate, strain, and the initial austenite grain size on the fractional softening due to SRX $\left(\mathrm{X}_{\mathrm{SRX}}\right)$. As can be seen, these curves exhibit typical sigmoidal behavior on the logarithm time.

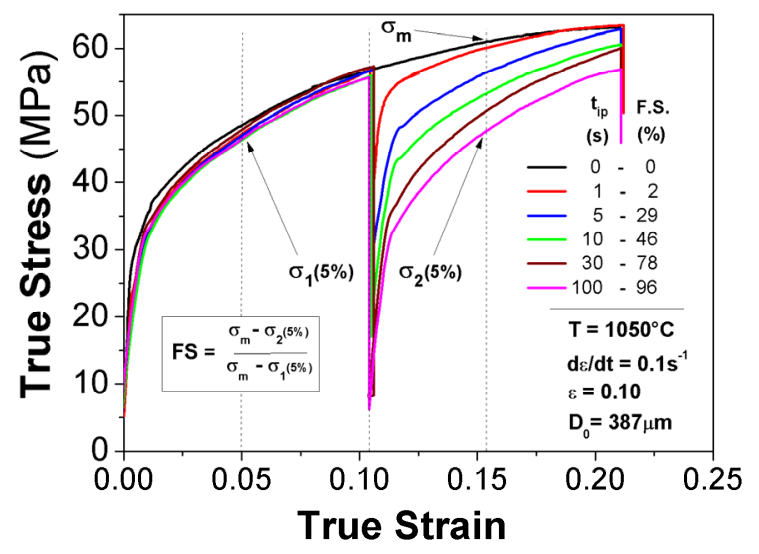

Figure 3. Effect of interpass time on the fractional softening for eutectoid steel subjected to double-hit hot compression tests performed at $1050^{\circ} \mathrm{C}$. 
Figure 4a presents the defect of deformation temperature in the range 1050 to $850{ }^{\circ} \mathrm{C}$ at a strain rate of $0.1 \mathrm{~s}^{-1}$, a 0.10 of strain and initial grain size of $387 \mu \mathrm{m}$ on the SRX kinetics. As can be seen, increasing the deformation temperature accelerates the kinetics of SRX and causes an increase in the recrystallized fraction $X_{\mathrm{SRX}}$. At $10 \mathrm{~s}$ interruption time, an increase in deformation temperature from 850 to $950{ }^{\circ} \mathrm{C}$ results in an increase in recrystallized fraction from 8 to $20 \%$ (i.e., a relative increase of $150 \%$ ). On the other hand, for an increase in deformation temperature from 950 to $1050{ }^{\circ} \mathrm{C}$, the recrystallized fraction increases from 20 to $46 \%$, and a relative increase of $130 \%$ is attained. These observations suggest that decreasing the deformation temperature from 1050 to $850{ }^{\circ} \mathrm{C}$, fractional softening (for a given strain rate, strain, and initial austenite grain size), causes a delay of about an order of magnitude in the rate of SRX.

The effect of strain rate on recrystallized fraction $X_{S R X}$ for the present steel deformed at $950{ }^{\circ} \mathrm{C}$ is very similar to the effect of the deformation temperature. As can be seen in Figure $4 b$, for a given interruption time, the $X_{\mathrm{SRX}}$ increases as the strain rate increased from 0.01 to $1 \mathrm{~s}^{-1}$. This type of behavior is usually associated with a decrease in the amount of dynamic recovery; therefore, an increase in the dislocation density as the strain rate increases. The dislocation density is related to the stored energy of deformation, which is responsible for the driving force for recrystallization [15]. According with the results that are presented in Figure $4 \mathrm{~b}$, the acceleration of softening rate caused by increasing the strain rate by two orders of magnitude is about one order of magnitude for a constant softening value in the present eutectoid steel.

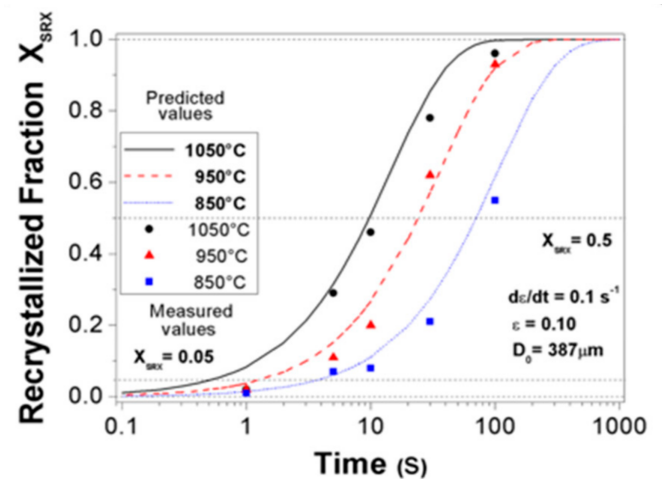

(a)

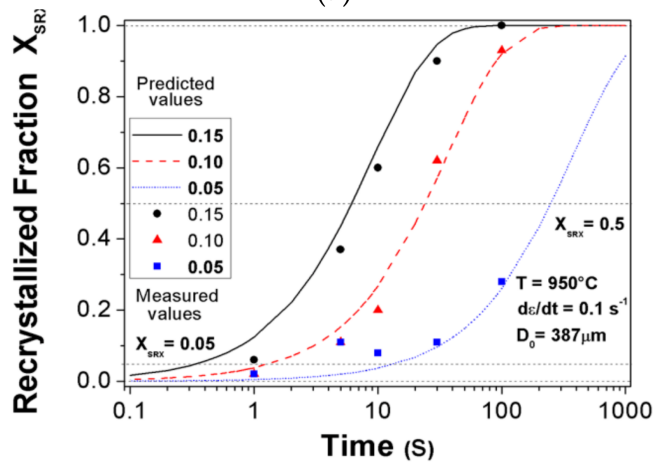

(c)

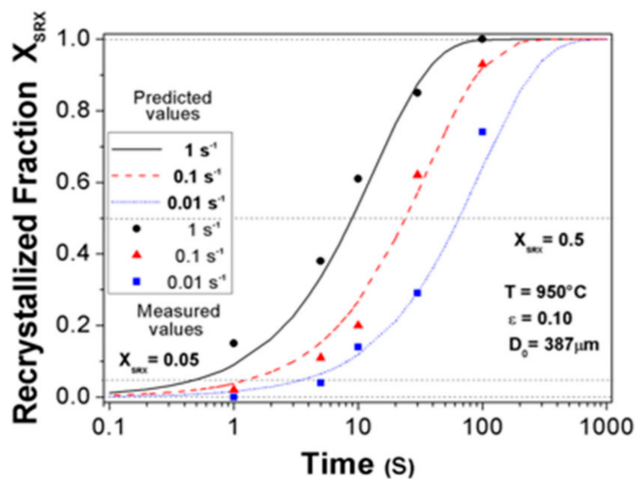

(b)

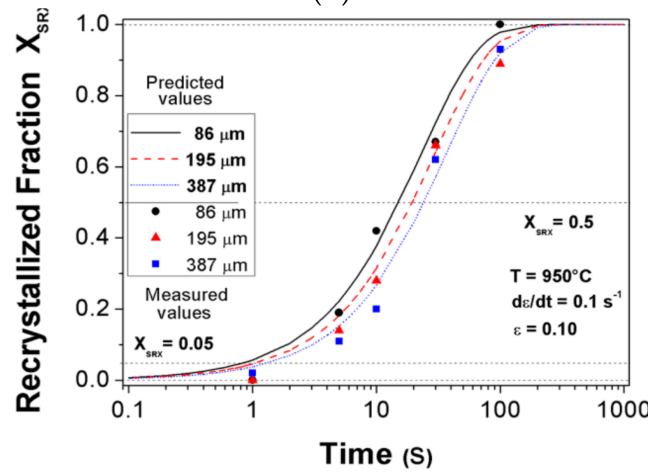

(d)

Figure 4. Comparison between experimental (isolated values) and predicted (curves) static recrystallizated fraction showing the dependence on (a) temperature, (b) strain rate, (c) strain, and (d) initial grain size.

Figure 4c illustrates the effect of strain on the recrystallized fraction (at constant deformation temperature, strain rate, and initial austenite grain size). Similar to the behavior that was observed for the effect of temperature and strain rate, increasing the magnitude of applied strain causes an increase in the recrystallized fraction. This is because larger strains produce greater dislocation densities 
and, consequently, increase the driving force that promotes recrystallization. It is interesting that the delay on the start of static recrystallization that was observed at smaller strains is stronger than that caused by a decrease in the deformation temperature or strain rate. The softening rate decreases by about 2.5 orders of magnitude by decreasing the applied strain from 0.15 to 0.05 for the same recrystallized fraction.

Finally, as shown in Figure $4 \mathrm{~d}$, the effect of the initial austenite grain size is small and, as the initial grain size increases, the recrystallized fraction decreases for a given interruption time. This effect can be attributed to the larger grain boundaries area that is associated with smaller initial grain size, which, in turn, increase the number of available nucleation sites for recrystallization [33,34]. It is noteworthy that, for the deformation conditions and the range of initial austenite grain sizes employed in this work, the effect of this microstructural characteristic on the static recrystallization rate is almost negligible and the curves that are illustrated in Figure $4 \mathrm{~d}$ practically overlap each other.

It is well known that static recrystallization is a process that involves nucleation and growth of new grains from a deformed microstructure. Therefore, from a phenomenological viewpoint, the recrystallized fraction $X_{S R X}$ can be described by the Avrami equation [35]. Equation (4) describes the complete kinetics behavior as a function of the time that is required to attain a recrystallization volume fraction of $50 \%\left(t_{0.5}\right)$. Equation (5) gives $t_{0.5}$ as a function of deformation parameters [36]:

$$
\begin{aligned}
& \mathrm{x}_{\mathrm{SRX}}=1-\exp \left(-0.693\left(\frac{\mathrm{t}}{\mathrm{t}_{0.5}}\right)^{n}\right. \\
& \mathrm{t}_{0.5}=A_{1} \varepsilon^{-p} \mathrm{Z}^{-q} \mathrm{~d}_{0}^{r} \exp \left(\frac{Q_{S R X}}{R \mathrm{~T}}\right)
\end{aligned}
$$

In Equation (4) $n$ is the Avrami exponent that represents the dependence of the recrystallized fraction on the nucleation and growth rates of new grains. $A_{1}, p, q$, and $r$ are the empirical constants that depend on the material, $\varepsilon$ is the applied strain, $d_{0}$ is the initial austenite grain size $(\mu \mathrm{m}), Z(\dot{\varepsilon} \exp$ $\left.\left(Q_{\text {def }} / R T\right)\right)$ is the Zener-Hollomon parameter $\left(\mathrm{s}^{-1}\right), Q_{\text {def }}$ and $Q_{S R X}$ are the apparent activation energies for deformation and recrystallization $(\mathrm{kJ} / \mathrm{mol}), R$ is the universal gas constant $(\mathrm{J} / \mathrm{mol} \cdot \mathrm{K})$, and $\mathrm{T}$ is the absolute temperature $(\mathrm{K})$.

\section{Determination of $n$}

According with Equation (4), a plot of $\ln \left(\ln 1 / 1-X_{\mathrm{SRX}}\right)$ as a function of $\ln (t)$ allows for the determination of $n$ from the slope of the straight lines. Figure 5 illustrates the resulting of $\ln \left(\ln 1 /\left(1-X_{S R X}\right)\right)-\ln (t)$ plot of various experimental conditions that were used in the present work. Assuming some experimental scatter, which is not significant, involved in the $n$ measurements within the ranges of the experimental deformation conditions, the average value of the Avrami exponent can be assumed to be independent of the deformation conditions. Other authors have extended this assumption, including the chemical composition of this steel [15]. As can be seen, from the data that are presented in the Figure 5, when the temperature and strain decrease, the $n$ value decreases. In contrast, when the strain rate decreases, the value of $n$ increases. These tendencies of little variation of $n$ have been reported by others researchers for different steels $[15,18,37]$. For the case of the effect of initial grain size, some investigators have reported reductions at $n$ from 2 to 1 as the initial grain size increases from 140 to $530 \mu \mathrm{m}$ [30], grain sizes from 17 to $40 \mu \mathrm{m}$ that produce $n$ values about 1 [15]. In the present study, increasing the austenite grain size from 86 to $387 \mu \mathrm{m}$ resulted in $n$ values that only slightly increase from 0.9 to 1 .

The resulting average $n$ value for the present study is 0.92. This $n$ value was used in Equation (4) to calculate the effect of temperature, strain rate, strain, and initial austenite grain size (Figure 4) on the static recrystallization kinetics of the steel investigated in this work. The calculated $X_{S R X}$ curves are plotted in Figure 4, together with the experimental data. As can be seen, the fitting is quite good. The $n$ 
average value for SRX obtained in the present work is similar to that reported by other researchers for different chemical compositions of steels $[15,17,18,21,29]$.

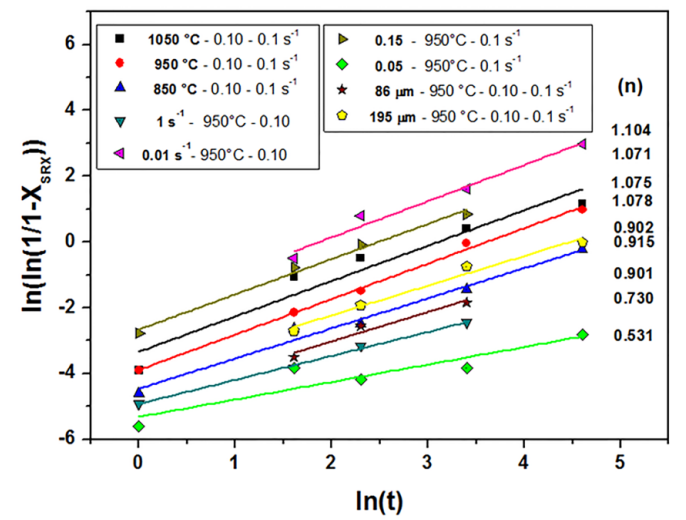

Figure 5. Effect of deformation conditions on the Avrami exponent $(n)$ for eutectoid steel.

Dependence of $\mathrm{t}_{0.5}$ on the Deformation Parameters

Logarithms were applied to both sides of Equation (5), obtaining the following expression $\ln \mathrm{t}_{0.5}=\ln A_{1}-p \ln \varepsilon-q \ln Z+r \ln \mathrm{d}_{0}+Q_{S R X} / R T$ to evaluate the dependence of $\mathrm{t}_{0.5}$ on deformation parameters. From this expression is possible to perform a single evaluation of the parameters $\varepsilon, Z, d_{0}$ and $\mathrm{T}$ as a function of $\mathrm{t}_{0.5}$ (which is obtained from the sigmoidal curves based on experimental values that are shown in Figure 4) and obtain the constants values $p, q, r$, and $Q_{S R X}$ that are the slopes of the lines in Figure 6.

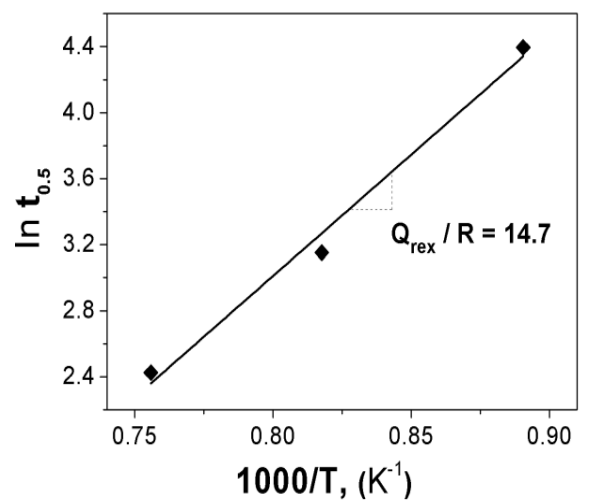

(a)

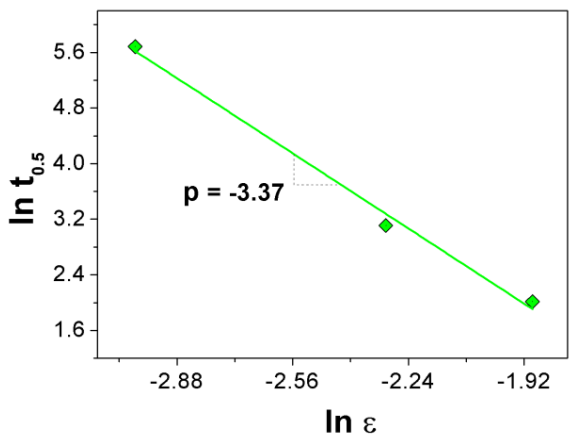

(c)

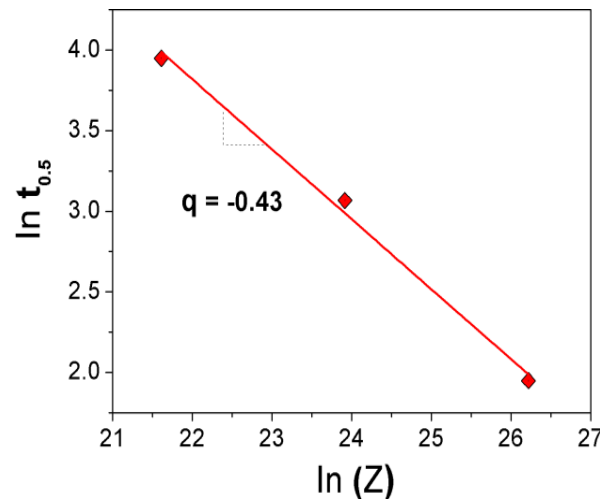

(b)

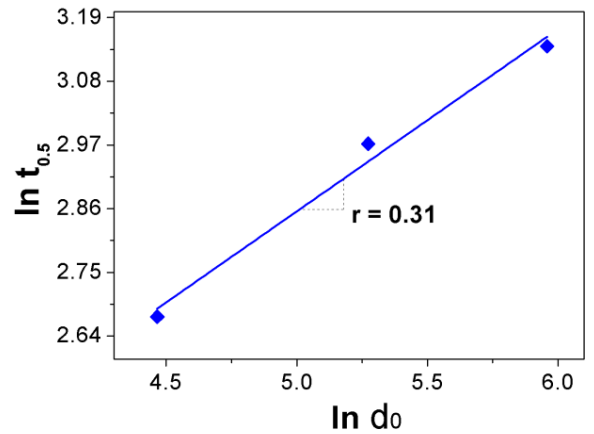

(d)

Figure 6. Dependence of the $50 \%$ softening $\left(\mathrm{t}_{0.5}\right)$ time on (a) temperature, (b) Zener-Hollomon parameter (Z), (c) strain, and (d) initial grain size. 
Static recrystallization is a thermally activated process that can be characterized by empirical apparent activation energy $Q_{S R X}$. The value of $Q_{S R X}$ is usually estimated by plotting the inverse temperature dependence of $\ln t_{0.5}$. As can be seen in Figure $6 a, Q_{S R X} / R$ is the slope of the resulting straight line and $R$ is the universal gas constant equal to $8.3144 \mathrm{~J} / \mathrm{mol} \cdot \mathrm{K}$. The value of $Q_{S R X}$ obtained in the present study is $122.2 \mathrm{~kJ} / \mathrm{mol}$. A large $Q_{S R X}$ value means that greater energies or times are required for starting the recrystallization process. Some authors report that most alloying elements have a retardation effect on recrystallization, with a greater influence played by $\mathrm{Nb}, \mathrm{Ti}$, and $\mathrm{Mo}[28,38]$. In the case of carbon (C) content, the main alloying element in steel, some researchers have reported a recrystallization acceleration effect [28,38], but other investigators suggested that $C$ and $V$ do not have a significant effect on recrystallization kinetics [39]. For example, Medina and Fabregue [38] studied the static recrystallization kinetic in steels with the following compositions: Fe-0.622C-0.546Mn-0.159SiandFe-0.849C-0.727Mn-0.258Si. The activation energy for the static recrystallization in each steel was found to be the same $(92 \mathrm{~kJ} / \mathrm{mol})$. The authors suggested that, in this case, the retarding effect that was caused by an increase in Mn content was balanced by the acceleration effect that was produced by the increment in $C$ content. As a result, the activation energy for static recrystallization in both steels was the same. In addition, a third steel composition was evaluated in which the carbon content was decreased, no Si was added, and the Mn content was slightly smaller than that the previous steel (0.191C-0.826Mn-0Si). As expected, the activation energy for SRX in this steel increases to $130 \mathrm{KJ} / \mathrm{mol}$, which indicated that the retardation effect of $\mathrm{Mn}$ dominatedthe kinetics of recrystallization. In contrast, Medina and Mancilla [39] investigated the effect of $\mathrm{C}$ content on the kinetics of static recrystallization for three steels with the following compositions: Fe-0.15C-0.74Mn-0.21Si, Fe-0.36C-0.82Mn-0.20Si, and Fe-0.53C-0.71Mn-0.21Si. The activation energies that were reported by these researchers for these compositions were 159,169 , and $158 \mathrm{~kJ} / \mathrm{mol}$. Therefore, they conclude that $C$ does not have a significant effect on the static recrystallization kinetics and the retardation effect of $\mathrm{Mn}$ and $\mathrm{Si}$ controls the process. The magnitude of the activation energy for static recrystallization obtained in the present work for eutectoid steel $(122 \mathrm{~kJ} / \mathrm{mol})$ is clearly within the range of values that were reported in the literature for steels of similar compositions. In this case, the observed value suggests that the static recrystallization process is controlled by the combined effect of retardation by $\mathrm{Mn}$ and acceleration by C. Finally, it is worthy to mention that much higher values of activation energy have been reported for medium carbon [18] (180 kJ/mol), low carbon [40] (248 and $263 \mathrm{~kJ} / \mathrm{mol})$, and low carbon $\mathrm{Nb}$ microalloyed steel [15] (404 kJ/mol).

Figure $6 \mathrm{~b}$ illustrates the magnitude of the effect of strain rate $(\mathrm{Z})$ on the time to obtain $50 \%$ of softening by static recrystallization. This plot assumes a simple empirical power law relationship $\left(\mathrm{t}_{0.5} \propto \mathrm{Z}^{-P}\right)$ between $\mathrm{t}_{0.5}$ and $\mathrm{Z}$. The constant $q$ resulting from the analysis of the experimental data obtained in the present work is 0.43 (this value is the same if it calculates as a function of $\dot{\varepsilon}$ ). This value is similar to those observed $(0.41,0.36,0.42$, and 0.33$)$ by Laasraoui and Jonas [15] for four low carbon steels with $\mathrm{Nb}, \mathrm{Cu}$, and B additions. Similarly, Barraclough and Sellars [30] reported a value of 0.38 for SRX behavior for a 304 stainless steel, Sun and Hawbolt [40] observed a value of 0.38 for two commercial plain carbon steels, Medina and Lopez [41] reported a value of 0.44 for a C-Mn and $\mathrm{V}$ microalloyed steels and, finally, Elwazri et al. [17] reported a value of 0.40 for a hypereutectoid microalloyed steel.

At deformations below the peak strain for DRX, softening is due to SRX (excluding the softening associated with recovery). Under this regimen of deformation, smaller strains than the peak strain in the flow curves, there is a relativity high dependence of $\mathrm{t}_{0.5}$ on strain $(\varepsilon)$ and it is illustrated in Figure $6 \mathrm{c}$. The constant $p$, the slope of the $\ln t_{0.5}-\ln \varepsilon$ relationship, is equal to -3.37 . This value is close to the range of values reported by Laasraoui and Jonas [15] from -3.55 to -3.81 . Other investigators reported strain exponent $p$ values of -2 and $-2.6[17,29,41]$. These low values can be explained in terms of the influence of the method used for the quantification of the fractional softening. The obtained data in the present work were also analyzed while using the $0.2 \%$ Offset method to calculate the softening fraction. The resulting strain exponent was -2.44 , which is similar to those reported by other researchers. 
Finally, according to the data presented in Figure $6 \mathrm{~d}$, there is a linear relationship between $\ln \mathrm{t}_{0.5}-\ln \mathrm{d}_{0}$ (initial austenite grain size). The slope that was calculated for this relationship is $r=0.31$. Values reported in the literature for this constant are usually between 1 for low carbon steels [21,40] and 2 for low carbon microalloyed steels [16,21]. However, for high carbon steels, there is no available information for this constant. As previously mentioned, increasing the initial grain size reduces the grain boundary area, which leads to a decrease in the density of potential nucleation sites for SRX (slowing down that process). However, from the results that were obtained in this work for high carbon steel, it appears that the recrystallization delay that was caused by increasing the initial austenite grain sizes is negligible in the range of 86 to $387 \mu \mathrm{m}$.

\subsection{Continuous Hot Compression Testing}

\section{Dynamically Recrystallized Grain Size}

The effect of temperature and strain rate on the DRX grain size was determined while using continuous axisymmetric hot compression tests at temperatures from 850 to $1050{ }^{\circ} \mathrm{C}$ and strain rates between 0.001 and $0.1 \mathrm{~s}^{-1}$. Compression specimens were rapidly quenched into water after true strains of 0.8 . The austenite grain size was estimated by standard metallographic techniques.

Figure $7 \mathrm{~d}$ presents the results of these experiments. As can be seen from the figure, when the deformation temperature increases at constant strain rate, the final austenite grain size increases. On the other hand, at constant temperature, the final grain size decreases when the strain rate increases.

The dependence of dynamically recrystallized grain size on temperature and strain rate follows the relationship [42]:

$$
d_{\mathrm{DRX}}=B Z^{-P_{1}}
$$

where $d_{\mathrm{DRX}}$ is the average refined grain size, $B$ and $p_{1}$ are constants and $\mathrm{Z}$ is the Zener-Hollomon parameter. Sellars and Tegart [43] proposed an expression that relates the $Z$ parameter and the peak stress $\left(\sigma_{p}\right)$ :

$$
\mathrm{Z}=\dot{\varepsilon} \exp \left(Q_{\text {def }} / R \mathrm{~T}\right)=A_{2}\left(\sinh \left(\alpha \sigma_{p}\right)^{n_{1}}\right)
$$

where $\alpha, A_{2}$, and $n_{1}$ are constants, $Q_{\text {def }}$ is the activation energy for deformation $(\mathrm{kJ} / \mathrm{mol})$, and $R$ is the universal gas constant $(\mathrm{J} / \mathrm{mol} \cdot \mathrm{K})$. This expression can be re-written in logarithm form as a function of strain rate:

$$
\ln \dot{\varepsilon}=n_{1} \ln \left(\sinh \left(\alpha \sigma_{p}\right)+\ln A_{2}-Q_{d e f} / R T\right.
$$

from this expression, it is possible to obtain the stress exponent $n_{1}$ by plotting the $\ln \dot{\varepsilon}$ term as a function of $\ln \left(\sinh \left(\alpha \sigma_{p}\right), \sigma_{p}\right.$ is the peak stress in the DRX flow curves. To determine $n_{1}, \alpha$ can be varied so as to minimize the standard deviation that is associated with fits of the experimental data to the above equation [42,44]. The values of $\alpha=0.0175$ and $n_{1}=4.16$ are obtained while using this procedure and are presented in Figure 7a. These values are similar those that were reported by other authors, such as $\alpha=0.020$ and $n_{1}=3.7$ for a Ti steel [44], $\alpha=0.016$, and $n_{1}=3.9$ for a Mo steel [42], $\alpha=0.012$ and $n_{1}=4.2$ for a Cu-Nb-B steel [45]. From the values of $\alpha$ and $n_{1}$ of this work, the activation energy of deformation $Q_{\text {def }}$ was obtained with the following expression:

$$
\ln \left(\sinh \left(\alpha \sigma_{p}\right)\right)=\left(Q_{d e f} / n_{1} R T\right)+\left(\ln \dot{\varepsilon} / n_{1}\right)-\left(\ln A_{2} / n_{1}\right)
$$

plotting $\ln \left(\sinh \left(\alpha \sigma_{p}\right)\right)$ as a function of $1000 / T$, as shown in Figure $7 \mathrm{~b}$, the average value from the slopes of the straight lines $\left(Q_{\text {def }} / n_{1} R T\right)=7.708$ results in $Q_{\text {def }}=266.6 \mathrm{~kJ} / \mathrm{mol}$. This value is similar to the activation energy that was reported by other researchers, such as $295+/-35 \mathrm{~kJ} / \mathrm{mol}$ for a Mo steel [42] and $290 \mathrm{~kJ} / \mathrm{mol}$ for a hypereutectoid steel [46].

Taking decimal logarithm twice on both sides of the Equation (6) and while plotting $\log d_{\mathrm{DRX}}$ as a function of $\log Z$, the exponent $p_{1}$ can be obtained from the slope of the linear relationship that was 
observed in Figure $7 \mathrm{c}$ and it is equal to -0.25 . The average value of $\mathrm{B}$ can be easily determined as $1.53 \times 10^{4}$, being derived from all experimental conditions.

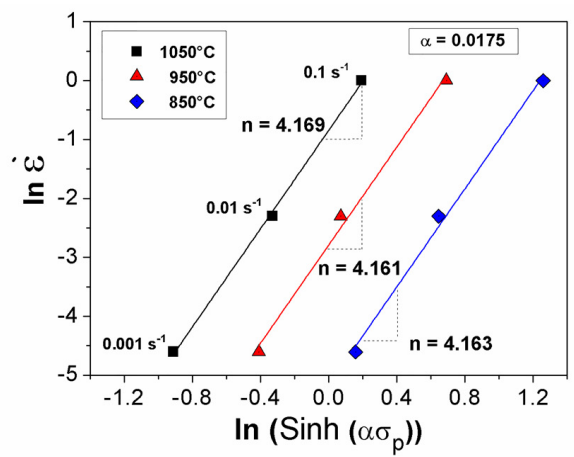

(a)

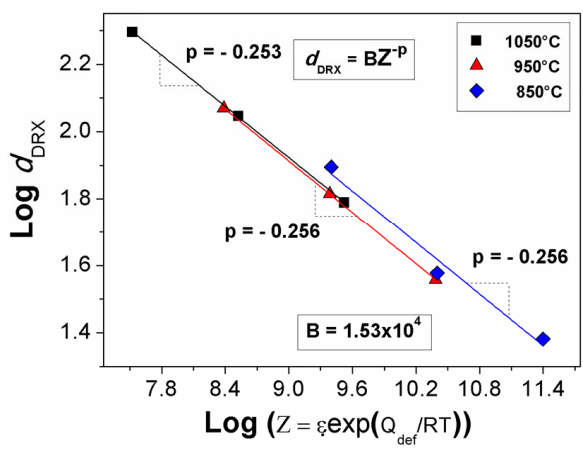

(c)

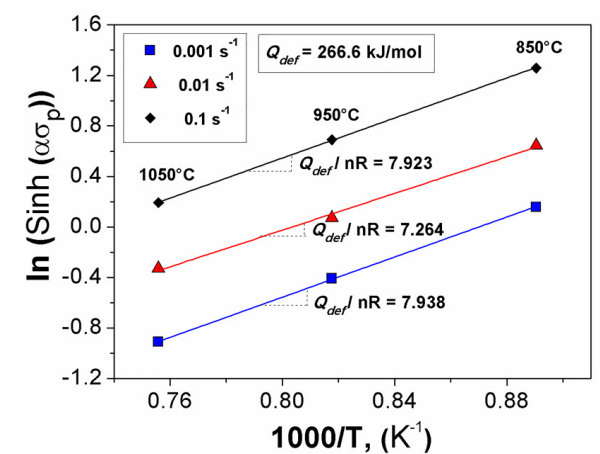

(b)

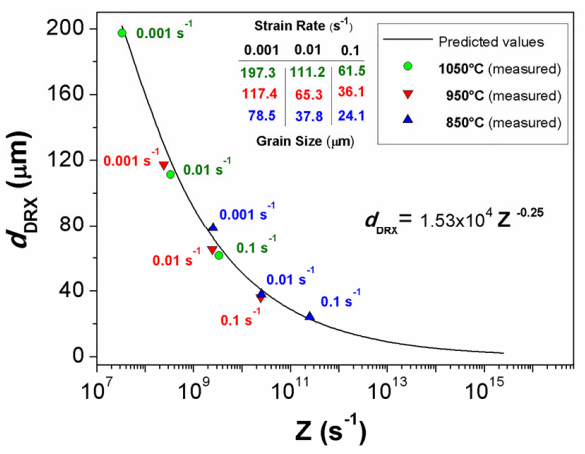

(d)

Figure 7. (a) Strain rate $(\dot{\varepsilon})$ dependence on peak stress $\left(\sigma_{p}\right)$ and $(\mathbf{b})$ effect of inverse of absolute temperature on the peak stress. (c) Determination of $B$ and $p_{1}$ under the dependence of $\log d_{\mathrm{DRX}}$ on $\log$ Z. (d) Experimental and predicted relationship of dynamically recrystallized austenite grain size $d_{\mathrm{DRX}}$ on Zener-Hollomon parameter Z.

Similar values of $B=1.6 \times 10^{4}$ and $p_{1}=-0.23$ for DRX of a C-Mn steel were reported by Hodgson and Gibbs [21], $B=1.7 \times 10^{4}$ and $p_{1}=-0.22$ for DRX of a high carbon steels by Elwazri et al. [46], and $B=2.55 \times 10^{4}$ and $p_{1}=-0.22$ for a hypereutectoid steel by Elwazri et al. [29] on MDRX.

Figure $7 \mathrm{~d}$ shows the refined austenitic grain size $\left(d_{\mathrm{DRX}}\right)$ dependence with Zener-Hollomon parameter $(Z)$. The peak strain $\varepsilon_{p}$ can be described as a function of the $Z$ and $d_{0}$ according to the following expression:

$$
\varepsilon_{p}=A_{3} \mathrm{Z}^{-q_{1}} \mathrm{~d}_{0}{ }^{r_{1}}
$$

where $A_{3}, q_{1}$, and $r_{1}$ are constants, $\mathrm{Z}$ is the Zener-Hollomon parameter and $\mathrm{d}_{0}$ is the austenitic initial grain size. The obtained values of $A_{3}, q_{1}$ and $r_{1}$ are $2.15 \times 10^{3}, 0.12$, and 0.3 , respectively. These values are similar to $2.5 \times 10^{3}, 0.10$, and 0.4 , as reported by Elwazri et al. [46] for eutectoid steel. A procedure that was similar to that used to determine the $B$ and $p_{1}$ constants in Equation (6) was employed to evaluate the constants $A_{3}, q_{1}$ and $r_{1}$ in Equation (8).

\subsubsection{Evaluation of Maximum Interpass Time Conditions for the Initiation and Propagation of DRX}

The experimental results that were obtained in the present work have been used to derive simple empirical equations (Equations (4) and (5)) to describe the fractional softening due to SRX measured from double-hit compression tests as a function of deformation parameters $\left(\mathrm{T}, \dot{\varepsilon}, \varepsilon\right.$, and $\left.\mathrm{d}_{0}\right)$. This kinetic equation provides the time intervals where the SRX rate is slow and, as a result, the strain might be 
accumulated from one deformation step to the other until the critical strain for DRX is reached or exceeded. It is the particular interest for the present study to consider the maximum interpass times compatible with DRCR under laboratory testing (low strain rates) that can be used to generate SRX kinetics equations for the high strain rates that are normally used in wire and rod industrial rolling. Wire and rod rolling strain rates can be as high as $1000 \mathrm{~s}^{-1}$ during the finishing passes. Thus, the laboratory measurements of softening during interpass times while using relativity low strain rates can be considerably lower than those that were observed at industrial strain rates. A way of estimating the amount of expected softening (that is the interpass time to attain a specific softening value) at strain rates used in industrial rod rolling from laboratory data is to use the developed kinetic equations. Alternatively, an interpass time amount correction can be used to account the strain rate differences. This kind of correction is justified since the time for $50 \%$ of softening $t_{0.5}$ due to SRX or MDRX are inversely proportional to the strain rate raised to an exponent $n_{2}$. Thus, the interpass time $t$ for a given $\mathrm{X} \%$ softening is also inversely proportional to a power of the strain rate. The interpass time for $\mathrm{X} \%$ softening in a laboratory $\left(t_{\mathrm{LAB}}\right)$ can be related to the interpass time for the same $X \%$ softening under conditions of hot rolling $\left(\mathrm{t}_{\mathrm{HR}}\right)$, as follows [42]:

$$
\mathrm{t}_{\mathrm{HR}}=\mathrm{t}_{\mathrm{LAB}}\left(\dot{\varepsilon}_{\mathrm{LAB}} / \dot{\varepsilon}_{\mathrm{HR}}\right)^{n_{2}}
$$

The $n_{2}$ exponent characterizes the strain rate effect on the kinetics of the SRX and MDRX. For the present study, the strain rate exponent $q$ for softening due to SRX, as calculated from Equation (5) is 0.43. The kinetics of MDRX was not investigated in this work. However, several studies concerning the softening due to this mechanism are reported in the literature for a large number of steel compositions. Most of these reports show that the strain rate exponent for softening due to MDRX can reach values that are twice as large as those obtained for softening due to SRX [29,40,42,47]. These observations indicate that post-dynamic softening process, such as MDRX, have great importance for the control of the microestructural evolution during multi-pass hot rolling operations [42]. Based on these reports, in the present study, an $n_{2}$ value of 0.86 was adopted for the post-dynamic softening in the investigated eutectoid steel.

Table 2 shows the maximum interpass times that produce $5 \%$ softening per pass due to SRX and MDRX. These values were calculated while using the kinetic Equations (4) and (5) and the time correction Equation (9) with constants that were derived from deformation experiments carried out in the laboratory. These calculations were performed for the following ranges of $T$, $\dot{\varepsilon}$, and $\varepsilon$ of 800 to $1050{ }^{\circ} \mathrm{C}, 0.01$ to $1000 \mathrm{~s}^{-1}$, and 0.05 to 0.15 , respectively. These ranges were selected to include the magnitudes of strain rates usually observed during industrial multi-pass hot rolling of rods.

In addition, the peak strain $\varepsilon_{p}$ from Equation (8) and the number of deformation passes that were needed to reach the peak strain for DRX (assuming a fractional softening of $5 \%$ in each pass) were also calculated. The final dynamically recrystallized grain size $\left(d_{\mathrm{DRX}}\right)$ for continuous deformation (up to a true strain of 0.8) was calculated while using Equations (6) and (7). The data presented in Table 2 allow for the derivation of suitable deformation conditions under which dynamic recrystallization controlled rolling can be feasible for the eutectoid steel investigated in the present work. 
Table 2. Maximum interpass times for dynamic recrystallization controlled rolling (DRCR) at 5\% softening per pass.

\begin{tabular}{|c|c|c|c|c|c|c|c|}
\hline \multicolumn{8}{|c|}{ Strain Rate $\left(\mathrm{s}^{-1}\right)$} \\
\hline \multicolumn{8}{|c|}{ Laboratory } \\
\hline Strain & Temperature $\left({ }^{\circ} \mathrm{C}\right)$ & \multicolumn{2}{|c|}{0.01} & \multicolumn{2}{|c|}{0.1} & \multicolumn{2}{|c|}{1} \\
\hline 0.15 & $950^{\circ} \mathrm{C}$ & & & $\begin{array}{l}\text { [1] } 0.363 \\
\text { [3] } 0.134\end{array}$ & [5] 1.5 & & \\
\hline 0.1 & $\begin{array}{l}1050^{\circ} \mathrm{C} \\
950{ }^{\circ} \mathrm{C} \\
850^{\circ} \mathrm{C}\end{array}$ & $\begin{array}{l}{[1] 3.829} \\
{[3] 1.422}\end{array}$ & $\begin{array}{c}\text { [4] } 0.171 \\
\text { [5] } 1.7 \\
\text { [6] } 69.0\end{array}$ & $\begin{array}{c}1] 0.573 \\
\\
{[3] 0.213} \\
{[1] 1.422} \\
{[2] 1.422} \\
{[3] 0.196} \\
{[1] 4.149} \\
- \\
\text { [3] } 1.541\end{array}$ & $\begin{array}{c}{[4] 0.178} \\
{[5] 1.7} \\
{[6] 63.7} \\
{[4] 0.226} \\
{[5] 2.2} \\
{[6] 38.8} \\
{[4] 0.299} \\
{[5] 2.9} \\
{[6] 21.6}\end{array}$ & $\begin{array}{l}\text { [1] } 0.528 \\
\text { [3] } 0.027\end{array}$ & $\begin{array}{c}\text { [4] } 0.298 \\
\text { [5] } 2.9 \\
\text { [6] } 21.8\end{array}$ \\
\hline 0.05 & $950^{\circ} \mathrm{C}$ & & & $\begin{array}{l}\text { [1] } 14.71 \\
\text { [3] } 5.465\end{array}$ & [5] 4.5 & & \\
\hline 0.05 & $800^{\circ} \mathrm{C}$ & & & $\begin{array}{c}\text { [1] } 78.95 \\
- \\
\text { [3] } 29.33\end{array}$ & $\begin{array}{c}\text { [4] } 0.351 \\
\text { [5] } 7.0 \\
{[6] 15.5}\end{array}$ & & \\
\hline
\end{tabular}

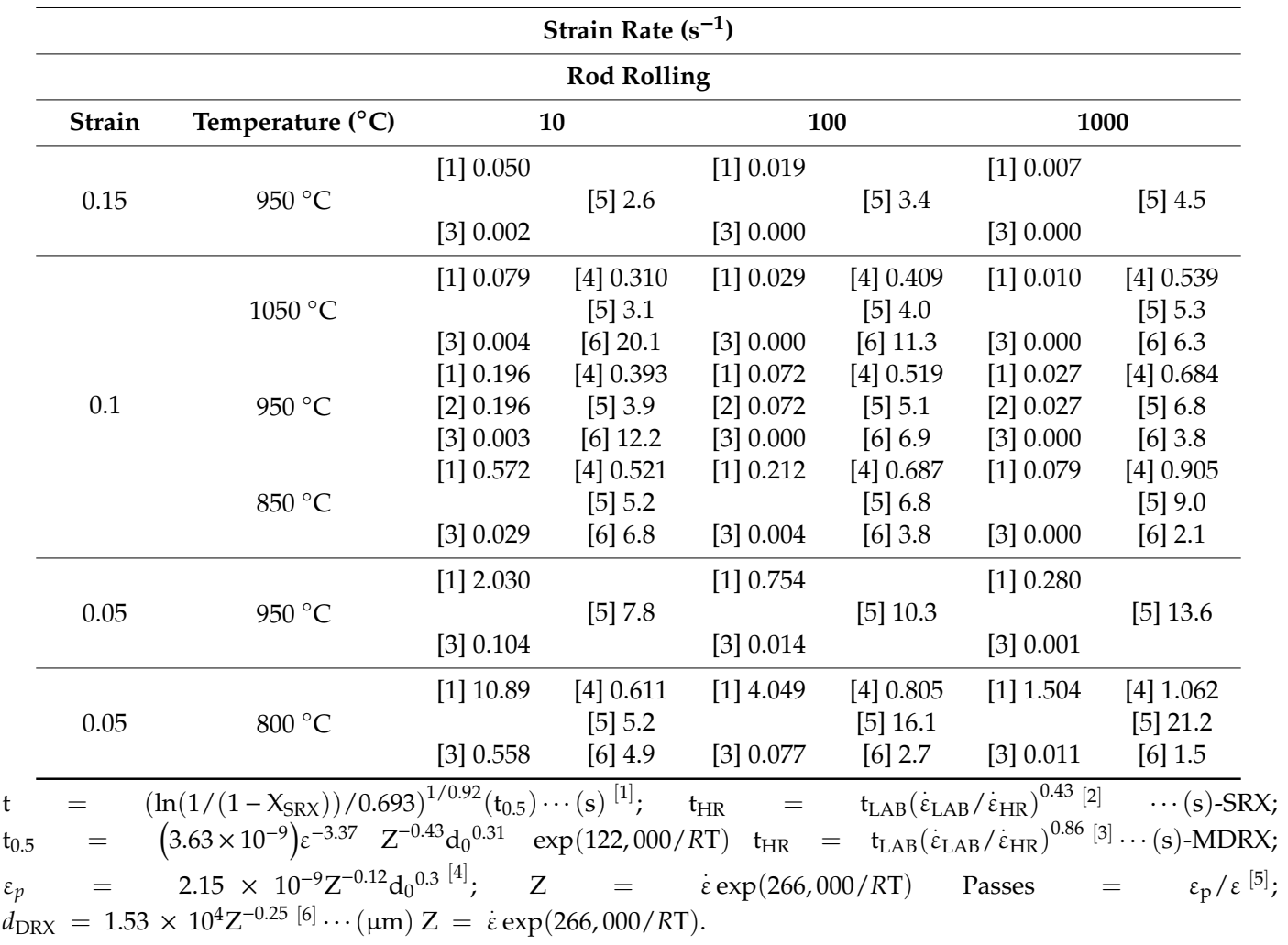

Allowing a maximum fractional softening of $5 \%$ between deformation passes under a given set of deformation conditions $\left(\mathrm{T}, \dot{\varepsilon}, \varepsilon\right.$ and $\mathrm{d}_{0}$ ), the calculated maximum interpass time must not be exceeded to avoid the restoration of the accumulated deformation up to that point. This is a simple exercise, but care must be taken to consider the magnitude of the accumulated strain prior to the interruption of deformation between passes. It must be clear that the controlling softening process is different, depending on the magnitude of the accumulated strain. When the accumulated strain is smaller than the peak strain $\varepsilon_{p}$, the controlling softening process during the interruption time is 
static recrystallization. On the other hand, for $\varepsilon>\varepsilon_{p}$, MDRX can occur during the interruption time. In this case, the strain rate exponent in the expression for the interpass time correction (Equation (9)) is twice as large as that for softening that is controlled by SRX. Figure 8 illustrates two ideal examples of dynamic recrystallization controlled rolling schedules with calculated interpass times on the experimental continuous flow curve at $850{ }^{\circ} \mathrm{C}$ and $0.1 \mathrm{~s}^{-1}$ and while assuming a $5 \%$ fixed softening per pass before and after peak strain, while applying strains of 0.1 for each deformation pass. In Figure $8 a$, the interpass times were calculated while assuming that the controlling softening process is SRX at $\varepsilon>\varepsilon_{p}$ and DRX for $\varepsilon>\varepsilon_{p}$. On the other hand, in Figure 8b, the interpass times were calculated while considering that SRX and MDRX are the controlling softening processes at $\varepsilon<\varepsilon_{p}$ and $\varepsilon>\varepsilon_{p}$, respectively.

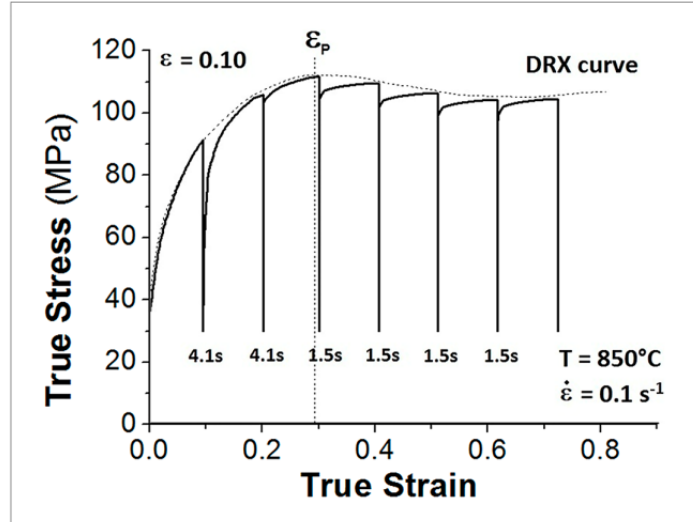

(a)

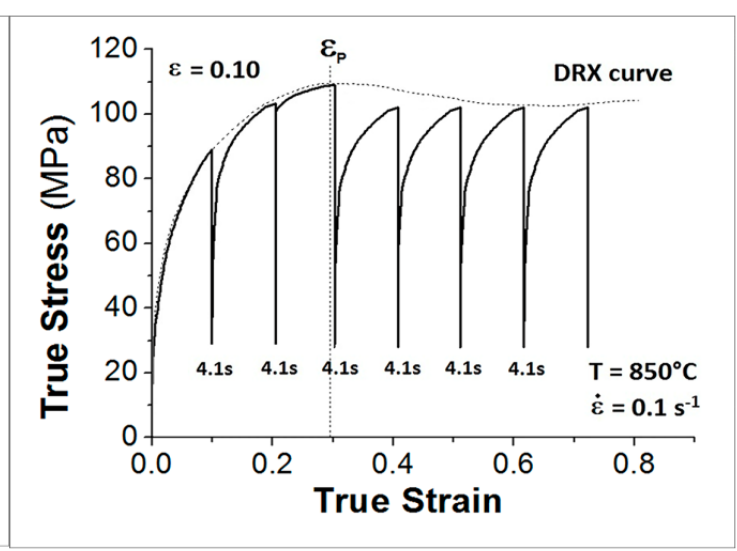

(b)

Figure 8. Calculated interpass times for ideal true stress-strain multi-pass diagrams on the experimental curve at $850^{\circ} \mathrm{C}$ and $0.1 \mathrm{~s}^{-1}$ showing the (a) DRCR and (b) Metadynamic Recrystallization Controlled Rolling (MDRCR) (Metadynamic Recrystallization controlled Rolling [42]) processes.

As can be seen in Figure 8a, a maximum interpass time of 4.149 s, which assumes that only produces a $5 \%$ of SRX softening, causes rapid strain accumulation and, after the 3rd pass, the strain exceeds the peak strain $\varepsilon_{p}$ and, therefore, the critical strain for DRX. Since MDRX is twice as fast as SRX, subsequent deformation stages with the same interpass time (4.149 s) would increase the fractional softening and, as consequence, the propagation of DRX would be interrupted. However, MDRX softening is avoided in DRCR process; therefore, as shown in Figure 8a, to keep the fractional softening to $5 \%$ for the $3 \mathrm{rd}$ and subsequence deformation passes, the time must be reduced to $1.541 \mathrm{~s}$. In this way, a steady state of DRX (such as the experimental continuous curve) and the final recrystallized grain size calculated of $21.6 \mu \mathrm{m}$ for this kind of process should be possible.

It is possible to produce the beginning of dynamic recrystallization under high strain rates conditions. However, maintaining the flow steady state regimen is difficult. This can be explained while considering that, at high strain rates, the calculated corrected times for post-dynamic softening in this study are practically zero for most conditions. Therefore, larger fractional softening due to MDRX must be considered. On the other hand, it is possible that incomplete DRX can take place after a given $\mathrm{X} \%$ softening due to MDRX. This possibility is illustrated in Figure $8 \mathrm{~b}$ for the same experimental continuous flow curve that is used to obtain the schedule shown in Figure 8a. From Figure 8b, the condition $\varepsilon=\varepsilon_{p}$ is reached in the 3rd deformation pass. This calculated point shows the onset of DRX and, as a result, MDRX takes the softening control. As the MDRX is twice as fast as SRX, after the beginning of DRX, it expected to generate an increase in fractional softening that would result in incomplete DRX for the same interpass time. Depending on the interruption time (no-corrected), this process can continue up to the total restoration of the accumulated deformation. Roucoules et al. referred to this last condition as Metadynamic Recrystallization Controlled Rolling (MDRCR) [42]. 
According to the data that are presented in Table 2, the only deformation condition compatible with DRCR at high industrial strain rates $\left(10,100\right.$, and $\left.1000 \mathrm{~s}^{-1}\right)$ is $800^{\circ} \mathrm{C}$ and 0.05 strain. This conclusion is drawn from the observation that the condition necessary for that process is that the maximum interpass time does not exceed the range from 0.558 to $0.011 \mathrm{~s}$ at 10 to $1000 \mathrm{~s}^{-1}$ and $800^{\circ} \mathrm{C}$. These interpass times are in the range that is usually observed in the pre-finishing and finishing stands of commercial rod mills [48]. Although the temperature is slightly lower than those observed in that practice and the strain per pass is also low when compared with those normally used in this kind of rolling process, the calculated maximum interruption times in the present work suggest that it is possible to initiate and maintain continuous DRX at isothermal and constant deformation conditions.

\section{Summary and Conclusions}

The following conclusions can be drawn from this study:

In the present work, a simple mathematical expression for the time that is needed for $50 \%$ of softening $\left(\mathrm{t}_{0.5}\right)$ as a function of $\mathrm{T}, \dot{\varepsilon}, \varepsilon$, and $\mathrm{d}_{0}$ was derived from double-hit compression tests for a steel of eutectoid composition.

1. The SRX rate was found highly sensitive to strain and, to a lesser degree, on strain rate.

2. The exponent values that describe the strain and strain rate effects are -3.39 and -0.43 , respectively. These are similar to values that are reported in the literature for a large number of steel compositions. Thus, there is a low dependence of these parameters exponents on chemical composition.

3. The dependence of $t_{0.5}$ on temperature and initial austenite grain size are lower than that observed for strain and strain rate parameters. The effect of temperature can be attributed to an accelerating effect of carbon on the kinetics of SRX. This conclusion is drawn from the observation that the apparent activation energy for SRX was relativity low $(122 \mathrm{~kJ} / \mathrm{mol})$. Although the interrupted tests did not exceed the critical strain $\left(\varepsilon_{\mathrm{c}}\right)$ to start the DRX (softening mechanism that does not depend on the initial austenite grain size for the final grain structure), the initial grain size effect on the SRX rate was very small or negligible within the investigated range.

4. The relationship between temperature, strain rate and the dynamically recrystallized grain size $\left(d_{\mathrm{DRX}}\right)$ was determined by an expression that relates the refined grain size and the Zener-Hollomon parameter $(Z)$ raised to an exponent. The recrystallized experimental grain size for a temperature range from 1050 to $850{ }^{\circ} \mathrm{C}$ and strain rates between 0.001 and $0.1 \mathrm{~s}^{-1}$ was 197.4 to $24.1 \mu \mathrm{m}$, respectively. Although, the predicted refined grain size could reach values as low as $1.5 \mu \mathrm{m}$ at $800{ }^{\circ} \mathrm{C}$ and $1000 \mathrm{~s}^{-1}$.

5. The maximum interpass times (calculated by the kinetic and time correction expression) that were estimated for a $5 \%$ of softening suggests that the initiation of the DRX for laboratory and rod rolling strain rates conditions can be achieved. However, after the onset of DRX, a large amount of MDRX softening is expected to take place (which is twice faster than SRX) and, in a DRCR process, the laboratory conditions are the only way to maintain continuous dynamic recrystallization.

Author Contributions: Conceptualization, C.F., A.S. and A.F.; Investigation, C.F.; Methodology, C.F.; Supervision, A.S., A.F. and G.A.; Writing—original draft, C.F.; Writing-review \& editing, C.F., A.S., A.F. and G.A.

Funding: This research was funded by Consejo Nacional de Ciencia y Tecnología (CONACYT), N.B. 261638.

Acknowledgments: Cesar A. Facusseh studies were sponsored by the National Council on Science and Technology (Consejo Nacional de Ciencia y Tecnología-México) and would like to thank them for the supportduring this project N.B. 261638.

Conflicts of Interest: The authors declare no conflict of interest.

\section{References}

1. Vervynckt, S.; Verbeken, K.; Lopez, B.; Jonas, J.J. Modern HSLA steels and role of non-recrystallization temperature. Int. Mater. Rev. 2012, 57, 187-207. [CrossRef] 
2. Hyzak, M.; Bernstein, M. The Role of Microstructure on the Strength and Toughness of Fully Pearlitic Steels. Metall. Mater. Trans. A 1976, 7, 1217-1224. [CrossRef]

3. Marder, R.; Bramfitt, B.L. The effect of morphology on the strength of pearlite. Metall. Mater. Trans. A 1976, 7 , 365-372. [CrossRef]

4. Alexander, D.J.; Bernstein, I.M. Cleavage Fracture in Pearlitic Eutectoid Steel. Metall. Mater. Trans. A 1989, 20, 2321-2335. [CrossRef]

5. Elwazri, A.M.; Wanjara, P.; Yue, S. The effect of microstructural characteristics of pearlite on the mechanical properties of hypereutectoid steel. Mater. Sci. Eng. A 2005, 404, 91-98. [CrossRef]

6. Modi, O.P.; Deshmukhb, N.; Mondal, D.P.; Jha, A.K.; Yegneswaran, A.H.; Khaira, H.K. Effect of interlamellar spacing on the mechanical properties of $0.65 \%$ C steel. Mater. Charact. 2001, 46, 347-352. [CrossRef]

7. Lewandowski, J.J.; Thompson, A.W. Effects of the Prior Austenite Grain Size on the Ductility of Fully Pearlitic Eutectoid Steel. Metall. Mater. Trans. A 1986, 17, 461-472. [CrossRef]

8. Bae, C.M.; Nam, W.J.; Lee, C.S. Effect of microstructural features on ductility in hypo-eutectoid steels. Script. Mater. 1999, 41, 605-610. [CrossRef]

9. Krauss, G. High carbon steels: Fully pearlitic microstructures and applications. In Steels: Processing, Structure, and Performance; ASM International: Chogar County, OH, USA, 2005; pp. 281-293.

10. Lesuer, D.R.; Syn, C.K.; Sherby, O.D.; Kim, D.K. Processing and Mechanical Behavior of Hypereutectoid Steel Wiresin Metallurgy. In Processing and Applications of Metal Wires; Paris, H.G., Kim, D.K., Eds.; TMS: Warrendale, PA, USA, 1996; pp. 109-121.

11. Hudson, W.B.; Wadsworth, K.J.P.; Bissen, C.T.; Heffingen, R.T. Process for Producing Patented Steel Wire. U.S. Patent 5873961, 12 May 1998.

12. Sakai, T.; Belyakov, A.; Kaibyshev, R.; Miura, H.; Jonas, J.J. Dynamic and post-dynamic recrystallization under hot, cold and severe plastic deformation conditions. Prog. Mater. Sci. 2014, 60, 130-207. [CrossRef]

13. Samuel, F.H.; Yue, S.; Jonas, J.J.; Barnes, K.R. Effect of Dynamic Recrystallization on Microstructural Evolution during Strip Rolling. ISIJ Int. 1990, 30, 216-225. [CrossRef]

14. Kestenbach, H.J.; Martins, G.S. Effect of Niobium on Austenite Recrystallization and Pearlite Colony Size in a Microalloyed Eutectoid Steel. Metall. Mater. Trans. A 1984, 15, 1496-1499. [CrossRef]

15. Laasraoui, A.; Jonas, J.J. Recrystallization of Austenite after Deformation at High Temperatures and Strain Rates-Analysis and Modeling. Metall. Mater. Trans. A 1991, 22, 151-159. [CrossRef]

16. Li, G.; Maccagno, T.M.; Bai, D.B.; Jonas, J.J. Effect of Initial Grain Size on the Static Recrystallization Kinetics of NbMicroalloyed Steels. ISIJ Int. 1996, 36, 1479-1485. [CrossRef]

17. Elwazri, M.; Essadiqi, E.; Yue, S. The Kinetics of Static Recrystallization in Microalloyed Hypereutectoid Steels. ISIJ Int. 2004, 44, 162-170. [CrossRef]

18. Garcia Mateo, C.; Lopez, B.; Rodriguez-Ibabe, J.M. Static Recrystallization Kinetics in Warm Worked Vanadium Microalloyed Steels. Mater. Sci. Eng. A 2001, 303, 216-225. [CrossRef]

19. Andrade, H.L.; Akben, M.G.; Jonas, J.J. Effect of Molybdenum, Niobium, and Vanadium on Static Recovery and Recrystallization and on Solute Strengthening in Microalloyed Steels. Metall. Mater. Trans. A 1983, 14, 1967-1977. [CrossRef]

20. He, X.L.; Djahazi, M.; Jonas, J.J.; Jackman, J. The Non-Equilibrium Segregation of Boron during the Recrystallization of Nb-Treated HSLA steels. Acta Metall. Mater. 1991, 39, 2295-2308. [CrossRef]

21. Hodgson, P.D.; Gibbs, R.K.A. Mathematical Model to Predict the Mechanical Properties of Hot Rolled C-Mn and Microalloyed Steels. ISIJ Int. 1992, 32, 1329-1338. [CrossRef]

22. Bao, S.-Q.; Zhao, G.; Yu, C.-B.; Chang, Q.-M.; Ye, C.-L.; Mao, X.-P. Recrystallization behavior of a $\mathrm{Nb}$-microalloyed steel during hot compression. Appl. Math. Model. 2011, 35, 3268-3275. [CrossRef]

23. Larrañaga, A.; Pereda, B.; Jorge, D.; Gutierrez, I. Austenite Static Recrystallization Kinetics in Microalloyed B Steels. Metall. Mater. Trans. A 2016, 47, 3150-3164. [CrossRef]

24. Kubota, M.; Kobayashi, Y.K.; Ushioda, K.; Takahashi, J. Effects of Alloying Elements on Static Recrystallization Behavior of Work-Hardened Austenite of High Carbon Low Alloy Steel. Mater. Trans. 2017, 58, 186-195. [CrossRef]

25. Kubota, M.; Kobayashi, Y.K.; Ushioda, K.; Takahashi, J. Effect of Carbon Content on Static Recrystallization Behavior of Work-Hardened Austenite in Low Alloy Steel and Its Mechanism. Mater. Trans. 2017, 58, 196-205. [CrossRef] 
26. Llanos, L.; Pereda, B.; Lopez, B.; Rodriguez, J.M. Hot deformation and static softening behavior of vanadium microalloyed high manganese austenitic steels. Mater. Sci. Eng. A 2016, 651, 358-369. [CrossRef]

27. Pereda, B.; Aretxabaleta, Z.; Lopez, B. Softening Kinetics in High Al and High Al-Nb-Microalloyed Steels. J. Mater. Eng. Perfom. 2015, 24, 1279-1293. [CrossRef]

28. Xu, Z.; Zhang, G.R.; Sakai, T. Effect of Carbon Content on Static Restoration of Hot Worked Plain Carbon Steels. ISIJ Int. 1995, 35, 210-216. [CrossRef]

29. Elwazri, M.; Wanjara, P.; Yue, S. Metadynamic and Static Recrystallization of Hypereutectoid Steel. ISIJ Int. 2003, 43, 1080-1088. [CrossRef]

30. Barraclough, D.R.; Sellars, C.M. Static recrystallization and restoration after hot deformation of type 304 stainless steel. Met. Sci. 1979, 13, 257-267. [CrossRef]

31. Perttula, J.S.; Karjalainen, L.P. Recrystallization rates in austenite measured by double compression and stress relaxation methods. Mater. Sci. Technol. 1998, 14, 626-630. [CrossRef]

32. ASTM Standards. E112-10; ASTM International: West Conshohocken, PA, USA, 2010; pp. 1-26.

33. Ruibal, E.; Urcola, J.J.; Fuentes, M. Static recrystallization kinetics, recrystallized grain size, and grain growth kinetics after hot deformation of a low-alloy steel. Z. Metallkd. 1985, 76, 568-576.

34. El Wahabi, M.; Gavard, L.; Montheillet, F.; Cabrera, J.M.; Prado, J.M. Effect of initial grain size on dynamic recrystallization in high purity austenitic stainless steels. Acta Mater. 2005, 53, 4605-4612. [CrossRef]

35. Avrami, M. Kinetics of Phase Change. I General Theory. J. Chem. Phys. 1939, 7, 1103-1112. [CrossRef]

36. Sellars, C.M.; Whiteman, J.A. Recrystallization and grain growth in hot rolling. Met. Sci. 1979, 13, $187-194$. [CrossRef]

37. Medina, S.F.; Mancilla, J.E. Determination of Static Recrystallization Critical Temperature of Austenite in Microalloyed Steels. ISIJ Int. 1993, 33, 1257-1264. [CrossRef]

38. Medina, S.F.; Fabregue, P. Activation Energy in the Static Recrystallization of Austenite. J. Mater. Sci. 1991, 26, 5427-5432. [CrossRef]

39. Medina, S.F.; Mancilla, J.E. Influence of Alloying Elements in Solution on Static Recrystallization Kinetics of Hot Deformed Steels. ISIJ Int. 1996, 36, 1063-1069. [CrossRef]

40. Sun, W.P.; Hawbolt, E.B. Comparison between Static and Metadynamic Recrystallization an Application to the Hot Rolling of Steels. ISIJ Int. 1997, 37, 1000-1009. [CrossRef]

41. Medina, S.F.; Lopez, V. Static Recrystallization in Austenite and Its Influence on Microstructural Changes in C-Mn Steel and Vanadium Microalloyed Steel at the Hot Strip Mill. ISIJ Int. 1993, 33, 605-614. [CrossRef]

42. Roucoules, C.; Yue, S.; Jonas, J.J. Softening and Microstructural Change Following the Dynamic Recrystallization of Austenite. Metall. Mater. Trans. A 1994, 25, 389-400. [CrossRef]

43. Sellars, C.M.; Mc-Tegart, W.J. On the mechanism of hot deformation. Acta Metall. 1966, 14, 1136-1138. [CrossRef]

44. Roucoules, C.; Yue, S.; Jonas, J.J. Effect of Alloying Elements on Metadynamic Recrystallization in HSLA Steels. Metall. Mater. Trans. A 1995, 26, 181-190. [CrossRef]

45. Laasraoui, A.; Jonas, J.J. Prediction of Steel Flow Stresses at High Temperatures and Strain Rates. Metall. Mater. Trans. A 1991, 22, 1545-1558. [CrossRef]

46. Elwazri, A.M.; Wanjara, P.; Yue, S. Effect of Carbon Content on Dynamic Recrystallization Behaviour of Plain Carbon Steels. Can. Metall. Q. 2004, 43, 507-512. [CrossRef]

47. Maccagno, T.M.; Jonas, J.J. Correcting for the Effects of the Static and Metadynamic Recrystallization during the Laboratory Simulation of Rod Rolling. ISIJ Int. 1994, 34, 607-614. [CrossRef]

48. Cetlin, P.R.; Yue, S.; Jonas, J.J.; Maccagno, T.M. Influence of Strain Rate on Interpass Softening During the Simulated Warm Rolling of Interstitial-Free Steels. Metall. Mater. Trans. A 1993, 24, 1543-1553. [CrossRef]

(C) 2019 by the authors. Licensee MDPI, Basel, Switzerland. This article is an open access article distributed under the terms and conditions of the Creative Commons Attribution (CC BY) license (http://creativecommons.org/licenses/by/4.0/). 